\title{
DETECTION OF SARS-COV-2 FROM SURFACE OF PATIENTS’ LEFTOVER FOOD PACKAGES AT A COVID-19 QUARANTINE CENTRE
}

\author{
Nadia Mohamad ${ }^{1 *}$, Yuvaneswary Veloo ${ }^{1}$, Muhammad Alfatih Pahrol ${ }^{1}$, Jeyanthi Suppiah², Rafiza \\ Shaharudin ${ }^{1}$ and Rohaida Ismail ${ }^{1}$ \\ Environmental Health Research Centre, Institute for Medical Research, Ministry of Health Malaysia, Shah Alam, \\ 40170, Selangor, Malaysia \\ ${ }^{2}$ Infectious Disease Research Centre, Institute for Medical Research, Ministry of Health Malaysia, Shah Alam, 40170, \\ Selangor, Malaysia
}

Corresponding author: Nadia Mohamad

Email: nadia@moh.gov.my

\begin{abstract}
In healthcare facilities, food waste and its packaging are mostly managed as non-infectious general waste. However, waste from SARS-CoV-2 positive patients, are treated as medical waste as they may be contaminated by the virus. We investigated the possibility of SARS-CoV-2 contamination from positive COVID-19 patients to their leftover food packages at a quarantine centre. Food packages surface was swabbed using prewetted cellular foam, placed into viral transport media and analysed using real time reverse transcription polymerase chain reaction. SARS-CoV-2 RNA was detected in two samples (4.5\%) from asymptomatic patients who were at day-2 positive SARS-CoV-2 with cycle threshold $(C t)$ value (RdRp/E), 34.96/35.72 and 37.1/36.48 respectively. Detection of SARS-CoV-2 supports that there is contamination to the waste. These poses risk of exposure as SAR-COV-2 survive on the surfaces, thus, safe handling and disposal of food waste should be maintained. However, further study involving viral culture should be explored to determine the viability of the SARS-CoV-2 from leftover food packages.
\end{abstract}

Keywords: COVID-19, pandemic, medical waste, food packages

\section{INTRODUCTION}

Current global COVID-19 pandemic has reshaped people's normal lifestyle worldwide. Restrictions, such as national lockdown, work from home, physical distancing and wearing mask in public places have become the new norms. Another cause of concern is risk of exposure to COVID-19 from environmental sources.

Studies on detection of SARS-CoV-2 from environmental surfaces in area surrounding COVID-19 patients have been conducted. Findings from these studies showed even asymptomatic patient may contaminate their surroundings which can be hazardous to other people1, 2. Faecal contamination in the toilet and air droplet by a COVID-19 patient has been proven to be the potential route of transmission from the environment ${ }^{3,4}$. Other sources of environmental exposure to COVID-19 are from healthcare and municipal wastes from COVID-19 treatment facilities $^{5}$. Improper management of their waste may promote spread of the disease. Therefore, infectious waste has to be managed properly. Waste from COVID-19 patients have been treated as medical waste creating significant increase in medical waste generation and has posed a big challenge to many countries ${ }^{5,6,7}$. Depending on the countries, these wastes may include increase use of personal protective equipment (PPE) as well as general waste like food from patients or suspected COVID-19 patients ${ }^{7}$. Some countries even treat waste from households during selfquarantine as medical waste ${ }^{6}$. Nevertheless, there is still lack of study that investigated presence of SARS-CoV-2 from food waste and their packaging.

In Malaysia, medical waste is classified as scheduled waste under the Environmental Quality (Scheduled Wastes) Regulations, 2005. There are scheduled waste contractors who are licenced to manage and dispose medical waste. Medical wastes generated from healthcare facilities, including COVID-19 waste, are mostly disposed by incineration. Other type of waste management such as pre-treated or recycling are not practised for COVID-19 waste ${ }^{8}$. Since the pandemic, generation of clinical waste had increased by $20 \%$, with more than $21.46 \%$ (over 6,600 tonnes) from total clinical waste was COVID-19 related waste in 2020, thus increasing the burden for their disposal?.

Following Standard Operating Procedure (SOP) at the point of study, food waste and its packages from COVID-19 patient's, together with needle, scalpels, personal protective equipment (PPE), swabs, gauzes, bandages and pathological waste had been treated as clinical waste. 
This contributed to overwhelming of licenced hazardous waste incineration plants to function at full capacity ${ }^{9}$. The cost for management of clinical waste had become an increased burden to healthcare financing, and there are also concerns on the effects of incineration to the environment.

An investigation was conducted at the end of January 2021 to investigate the presence of SARSCoV-2 from patient's food packages. The findings are expected to help stakeholders in exploring alternative ways to manage food waste and its packaging.

\section{METHOD}

The COVID-19 Quarantine and Treatment Centre in Selangor has been in operation since late 2020, to cater for low risk and mild COVID-19 patients. The centre has an average number of more than 4000 patients on treatment daily. Within two months since the operation begun, the total cumulative patients that were admitted was more than 35,000 . Meals were served at regular interval three times a day using sustainable food packages. Food was packed in the disposable plastic food containers with lid, drinking water was served in $250 \mathrm{ml}$ plastic bottle and diposable plastic spoon and fork were also given to patients. Considering this is the first study conducted on food packages and without any reference, a small sample were use for prelimany investigation. The main quarantine and treatment centre in Malaysia was selected for sampling as it generates the heaviest weight of COVID-19 waste.

\section{Food container sampling}

The sampling activity was conducted on $26^{\text {th }}$ January 2021 in the quarantine and treatment centre from $10.00 \mathrm{am}$ to $2.00 \mathrm{pm}$ local time. Food containers were taken from 18 patients in two separate halls. They were randomly chosen from newly admitted COVID-19 patients, with less than a week of admission, and with mild symptoms or without symptoms. Since Hall 1 was not provided with utensils, we had taken 10 samples from food containers and 10 samples from drinking bottles. While in Hall 2, samples were taken from eight food containers, eight drinking bottles and additional eight sets of utensils making a total of 44 samples. There was no direct contact between the investigators and patients. Chosen food packages were collected directly after patients had taken their lunch by the centre's staffs. Samples were collected from surface of food packages using two cellular foam swab prewetted with viral transport media (VTM) and placed into one $1 \mathrm{ml} \mathrm{VTM}$. All samples were collected and immediately transported to the laboratory.

\section{Laboratory analysis}

Viral inactivation by heat was done on all samples prior to RNA extraction in using QIAamp Viral RNA Mini Kit (Qiagen, Hilden, Germany), according to manufacturer's instructions ${ }^{10}, 11$. For detecting the presence of SARS-CoV-2, real-time reverse transcription polymerase chain reaction (RT-PCR) using Real-Q 2019-nCoV detection kit was used. Virus regions from RNA dependent RNA polymerase (RdRP) gene and envelope $(\mathrm{E})$ gene were selected as target areas. $5 \mu \mathrm{L}$ of extracted RNA was reverse transcribed, and amplified by PCR under the following cycle conditions: 1 cycle at $50^{\circ} \mathrm{C}$ for 30 minutes, 1 cycle at $95^{\circ} \mathrm{C}$ for 15 minutes, 40 cycles at $95^{\circ} \mathrm{C}$ for 15 seconds, and $62^{\circ} \mathrm{C}$ for 45 seconds using Real-Time System Thermal Cycler (BIO RAD).

\section{RESULTS}

A total of 44 samples were taken from food containers, utensils and water bottles within two groups; one group with symptoms and another one without any symptoms. Detection rate for evidence of SARS-CoV-2 was $4.5 \%$ (2 out of 44 samples were positive for both genes of SARS-CoV2 ). One was collected from the surface of utensils and another one from the surface of drinking bottle. Both samples were from asymptomatic COVID-19 patients. The cycle threshold (Ct) value (RdRp/E) for the positive samples were $34.96 / 35.72$ and $37.1 / 36.48$ respectively indicating low viral load. Table 1 showed PCR result from the surface of food packaging.

\section{DISCUSSION}

In April 2020, the WHO Interim guidance suggested that it is doubtful that people can be infected with COVID-19 from food or food packaging ${ }^{12}$. However, they also emphasize for food industry to take preventive measure to eliminate risk of surface and food package from becoming contaminated with the virus as there is risk of becoming infected from touching them ${ }^{12}$. To our knowledge, there is no study to date that examined presence of the virus on surface of leftover food packaging from COVID-19 patients. However, a study from Qingdao Port reported that cold-chain transportation in food industry had cause transmission of the virus ${ }^{13}$. Two workers found positive SARS-CoV-2 with no close contact or foreign personal contact history, yet, they had history of handling frozen cod which was found to be positive for SARS-CoV-2 $(11.9 \%)^{13}$.

Findings from this investigation showed that $4.5 \%$ of leftover food packages were found positive for SARS-CoV-2. 
Table 1: RT-PCR results from surface sampling of leftover food packages

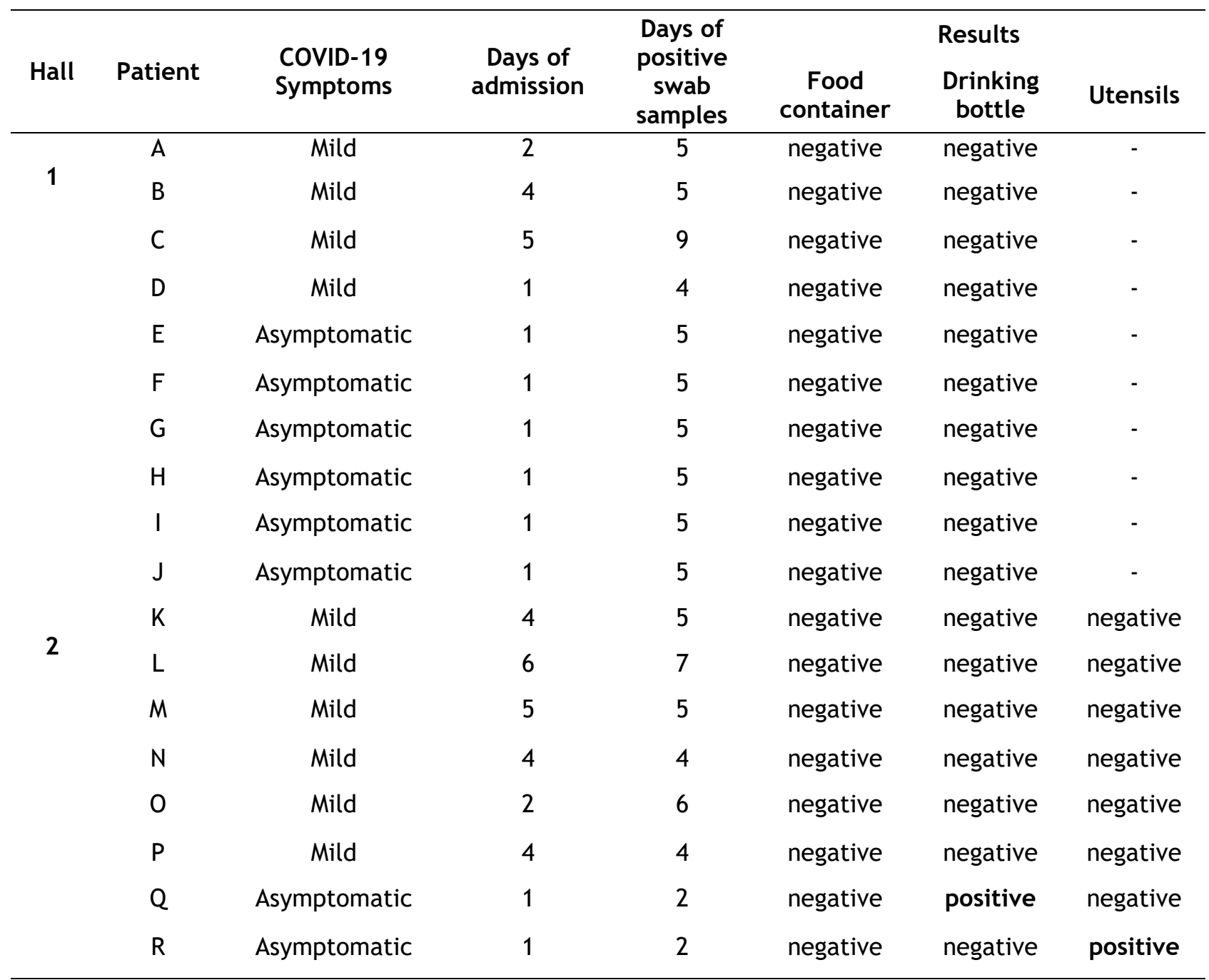

There is no direct comparison for food packages study, however this finding was similar with environmental surface sampling study in 2020 that showed $5.0 \%$ positive RT-PCR for SARS-CoV-2 in isolation room where patients with COVID-19 were treated ${ }^{14}$. Another study suggests the contamination depends on the infection control measure as none of the surface sampling were positive in hospital settings as they may have prior disinfection but $16.7 \%$ detected positive where there was no disinfection done before the sampling ${ }^{11}$.

While possibility of transmitting infection may be less compared to symptomatic individuals ${ }^{15}$, both positive samples detected were from asymptomatic patients. There are evidence suggesting that asymptomatic and presymptomatic patients could cause dissemination of the disease. A study in England discovered that there was no difference in the presence of virus in patient with symptoms and without symptoms ${ }^{16}$. This finding was also in agreement with an environment sampling study in China which detected SARS-CoV-2 positive at bedrail, pillow, bedsheet and air exhaust outlet in an asymptomatic patient's room, suggesting that patients with no symptom also could disseminate the virus ${ }^{1}$.

Even though the samples were taken from day-2 to day-9 of positive clinical test, both positive samples detected were from those at day- 2 of positive clinical swab samples. As they had no symptoms, it is difficult to determined when the infection began. However, the detection at early stage of diagnosis corresponds to the study in China that indicate viral shedding begin before onset of symptoms and later decreasing, implying that infectiousness peaked around the day of appearance of clinical presentation (about 2 days before and 1 day after onset) of the disease and decline over time after developing the symptom ${ }^{17}$, 18. The rate of positive detection also decreases the longer time passed ${ }^{19}$. Comparing the infection in weeks of duration, the first week yielded lower $\mathrm{Ct}$ value compared to the second week $^{16}$. The detection SARS-CoV-2 among asymptomatic patients' food packages during early diagnosis emphasize the importance of current policy of incorporating testing of asymptomatic and presymptomatic contact for COVID-19. 
The $\mathrm{Ct}$ value detected from this study were $34.96 / 35.72$ and $37.1 / 36.48$. No further culture was proceeded due to the high $\mathrm{Ct}$ value result which indicated low viral load, therefore the possibility that they could be cultured were also low. Estimation of virus propagation with $\mathrm{Ct}$ value of $>35$ was $8.3 \%{ }^{16}$. However, according to the Centres for Disease Control and Prevention (CDC), $\mathrm{Ct}$ value cannot predict whether the result is infectious as the value can also be affected with other factors, including method of sample collection and handling ${ }^{20}$. Thus, we cannot conclude the findings as infectious or not.

The limitations of this investigation were the small number of samples and it was conducted at only one quarantine centre. Based on findings of this investigation and to strengthened the evidence, we suggest to conduct a study which takes into consideration the appropriate sample size calculation and sampling sites. Other limitations include, sampling was done only among asymptomatic patients and patients with mild symptoms. We did not do simultaneous nasopharyngeal swab together with sampling of the patients' food containers. Future study could consider taking serial sampling of patients from day-1 of admission till discharge to record viral shedding pattern on different days. Additionally, we also did not proceed with culturing the virus to determine viability and infectiousness.

\section{CONCLUSION}

The results suggest that there was contamination from COVID-19 patients to their leftover food packages, in which the finding supports the policy for waste management to be treated as clinical waste. Presence of RT-PCR positive for SARS-CoV2 indicate that safe handling of food waste and its packages waste is crucial. The risk of transmitting the COVID-19 should be considered when exploring alternative ways to handle them. Further study as discussed above could be considered to strengthen findings of this investigation. Ministry of Health should also look into alternative methods to handle food waste appropriately which can reduce its cost and also to avoid overwhelming of waste treatment facilities.

\section{ACKNOWLEDGEMENTS}

This investigation was supported by Ministry of Health Malaysia. Laboratory analysis was performed at the Institute for Medical Research, Ministry of Health Malaysia. We would like to thank the Director General of Health Malaysia for his permission to publish this article. We also wish to thank Zohara Amin, Zuraidah Abd Halim and Priyavani Netheyanathan, for assistance during field sampling, and also Cathrinena Anak Robun and Sharipah Sharif for assisting in laboratory analysis.

\section{COMPETING INTERESTS}

There is no conflict of interest.

\section{SOURCE OF FUNDING}

No funding.

\section{REFERENCE}

1. Wei L, Lin J, Duan $X$, et al. Asymptomatic COVID-19 Patients Can Contaminate Their Surroundings: an Environment Sampling Study. mSphere 2020; 5(3)e00442-20.

2. Ong SWX, Tan YK, Chia PY, et al. Air, surface environmental, and personal protective equipment contamination by severe acute respiratory syndrome coronavirus 2 (SARS-CoV-2) from a symptomatic patient. Jama 2020; 323(16):1610-1612.

3. Young BE, Ong SWX, Kalimuddin S, et al. Epidemiologic features and clinical course of patients infected with SARSCoV-2 in Singapore. Jama 2020; 323(15):1488-1494.

4. Chia PY, Coleman KK, Tan YK, et al. Detection of air and surface contamination by SARS-CoV-2 in hospital rooms of infected patients. Nat Commun 2020; 11(1):2800

5. Sarkodie SA, Owusu PA. Impact of COVID-19 pandemic on waste management. Environ Dev Sustain 2020; 23:7951-7960.

6. ESCAP. The safe waste treatment for COVID-19: Lessons from the Republic of Korea. United Nations Economic and Social Commission for Asia and the Pacific 2020. https: / /www.unescap.org/resources/sa fe-waste-treatment-covid-19-lessonsrepublic-korea (accessed 8 March 2021).

7. Wei G, Manyu L. The Hidden Risks of Medical Waste Management and COVID19. 2021. https: / / www.waste360.com/medicalwaste/hidden-risks-medical-waste-andcovid-19-pandemic (accessed 8 March 2021).

8. Agamuthu $\mathrm{P}$, Barasarathi J. Clinical waste management under COVID-19 
scenario in Malaysia. Waste Manag Res 2021; 39(suppl 1):18-26.

9. The Star. Over 6,600 tonnes of Covid-19 clinical waste generated in 2020 . The Star 2021. https: / /www.thestar.com.my/news/fo cus/2021/01/03/over-6600-tonnes-ofcovid-19-clinical-waste-generated-in2020 (accessed 10 March 2021).

10. Kim JM, Chung YS, Jo HJ, et al. Identification of Coronavirus Isolated from a Patient in Korea with COVID-19. Osong Public Health Res Perspect 2020; 11(1):3-7.

11. Lee SE, Lee DY, Lee WG, et al. Detection of Novel Coronavirus on the Surface of Environmental Materials Contaminated by COVID-19 Patients in the Republic of Korea. Osong Public Health Res Perspect 2020; 11(3):128-32.

12. WHO. COVID-19 and Food Safety: Guidance for Food Businesses. World Health Organization 2020. https://www. who.int/publications/i/it em/covid-19-and-food-safety-guidancefor-food-businesses (accessed 5 March 2021).

13. Liu $P$, Yang $M$, Zhao $X$, et al. Cold-chain transportation in the frozen food industry may have caused a recurrence of COVID-19 cases in destination: Successful isolation of SARS-CoV-2 virus from the imported frozen cod package surface. Biosaf Health 2020; 2(4):199201.

14. Cheng VCC, Wong SC, Chan VWM, et al. Air and environmental sampling for SARS-CoV-2 around hospitalized patients with coronavirus disease 2019 (COVID19). Infect Control Hosp Epidemiol 2020; 41(11):1258-65.

15. WHO. Transmission of COVID-19 by asymptomatic cases 2020. World Health Organization 2020.

http://www.emro.who.int/healthtopics/corona-virus/transmission-ofcovid-19-by-asymptomatic-cases.html (accessed 5 March 2021).

16. Singanayagam $A$, Patel $M$, Charlett $A$, et al. Duration of infectiousness and correlation with RT-PCR cycle threshold values in cases of COVID-19, England, January to May 2020. Euro Surveill 2020; 25(32):2001483.
17. He X, Lau EHY, Wu P, et al. Temporal dynamics in viral shedding and transmissibility of COVID-19. Nat Med 2020; 26(5):672-5.

18. To KKW, Tsang OTY, Leung WS, et al. Temporal profiles of viral load in posterior oropharyngeal saliva samples and serum antibody responses during infection by SARS-CoV-2: an observational cohort study. Lancet Infect Dis 2020; 20(5):565-74.

19. Yamagishi T, Ohnishi M, Matsunaga N, et al. Environmental Sampling for Severe Acute Respiratory Syndrome Coronavirus 2 During a COVID-19 Outbreak on the Diamond Princess Cruise Ship. J Infect Dis 2020; 222(7):1098-102.

20. CDC. Frequently Asked Questions about Coronavirus (COVID-19) for Laboratories. Centers for Disease Control and Prevention 2020. https: / / www.cdc.gov/coronavirus/201 9-ncov/lab/faqs.html (accessed 5 March 2021) 